\title{
ACUTE LEFT AURICULAR FAILURE
}

\author{
BY \\ CRIGHTON BRAMWELL AND A. MORGAN JONES
}

From the Cardiographic Department, Manchester Royal Infirmary

Received April 1, 1944

Various hypotheses have been advanced to account for the occurrence of acute pulmonary œdema in association with mitral stenosis during pregnancy, but none is entirely satisfactory. The following two cases are recorded because they present certain clinical and pathological features that may help to throw some light on the subject.

\section{CASE ReCords}

Case 1, M. H. H. A primigravida, aged 37, was admitted to hospital, in the fifth month of pregnancy, on account of recurrent attacks of acute dyspnœa with hæmoptysis.

She gave a history of rheumatic fever at the age of seven but, apart from slight shortness of breath on exertion, had been free from symptoms until the third month of pregnancy when she became increasingly dyspnœic and developed a persistent cough with blood-streaked sputum. Two months later she had a sudden acute attack of dyspnœa at rest and coughed up a moderate amount of bright red blood. Three further attacks occurred during the next three days and she was admitted to St. Mary's Hospital, Manchester, under the care of Dr. J. W. A. Hunter, very collapsed, extremely dyspnœic, and coughing up considerable quantities of pink frothy sputum. The radial pulse was only just palpable and there was a trace of œedema at the ankles. Moist sounds were present all over the chest. The blood pressure was 100/70. The clinical picture was that of acute left-sided heart failure. Under treatment her condition improved rapidly and next morning there were only scattered moist sounds in the chest with slight hæmoptysis; the œdema had disappeared and there was no systemic venous engorgement. The heart was grossly enlarged, but its rhythm was regular, and there was a loud apical presystolic but no other diastolic murmur.

With rest in bed her condition steadily improved, the dyspnœa subsided, and the hæmoptysis ceased in a few days. She remained well for two weeks, but then, without apparent cause, became acutely dyspnœic and coughed up a considerable quantity of blood. The suddenness of this relapse suggested the possibility of a pulmonary embolus. She failed to respond to treatment, developed severe pulmonary œdema, and died in a few hours.

Autopsy was performed by Dr. F. A. Langley. The lungs were grossly œdematous, but there was no sign of recent pulmonary embolism, nor of old infarction. The heart weighed $400 \mathrm{~g}$. There was a button-hole stenosis of the mitral valve, measuring $15 \times 3 \mathrm{~mm}$. The aortic valve was slightly scarred and the cusps were adherent for a short distance from their bases. The pulmonary and tricuspid valves were healthy. The left auricle was considerably dilated and hypertrophied, its wall being $4 \mathrm{~mm}$. thick. The right ventricle also was considerably hypertrophied, the wall being $9 \mathrm{~mm}$. thick. The pulmonary arteries were moderately atheromatous. Apart from some cortical congestion the kidneys were normal.

The estimated age of the fœtus was $6 \frac{1}{2}$ months.

Case 2, M. McA. A primigravida, aged 34, was first seen in September 1941 when $4 \frac{1}{2}$ months pregnant. She gave no history of rheumatic fever, but had had occasional swelling of the ankles since the age of 15. She had been somewhat breathless on exertion for several years, and more so during pregnancy. On examination there was a coarse apical presystolic thrill, accompanied by a loud crescendo murmur. Moist sounds were present at the base of the lungs, but there was no evidence of right ventricular failure.

A cardiogram showed slight right axis deviation with sinus rhythm. Tele-radiograms showed some enlargement of the pulmonary conus, moderate enlargement of the left auricle, and considerably increased vascular markings in the lungs. A therapeutic abortion was performed at St. Mary's Hospital and she was advised to have no more children.

A year later she was re-admitted to St. Mary's Hospital under the care of Dr. J. W. A. Hunter, as 
an urgency, $4 \frac{1}{2}$ months pregnant, with right ventricular failure, considerable œdema, and an enlarged tender liver. When seen by one of us (A. M. J.) five days later, the œedema had subsided and the venous engorgement had greatly lessened, but she was still very dyspnœic. The heart rhythm was regular, and there was a coarse apical presystolic thrill accompanied by an exceptionally loud and harsh crescendo murmur. Termination of pregnancy was advised when her condition had improved. Three weeks later she was given 1/3 of a grain of omnopon and 1/150 of a grain of scopolamine prior to therapeutic abortion, and collapsed with very slow respiration. Severe right ventricular failure with gross œdema rapidly developed. When her condition had improved somewhat she was transferred to the Manchester Royal Infirmary (September 30). She was then only slightly dyspnœic at rest, but had œdema up to the groins and in the hands, with free fluid in the abdomen. The percussion note was impaired and there were moist sounds at the bases of the lungs. The blood pressure was 115/75. A cardiogram showed an increased degree of right axis deviation compared with her previous record. Under treatment she improved slowly, but on October 6 she was again given 1/4 of a grain of morphia, and about an hour later became extremely dyspnœic and almost pulseless. With theophylline-ethylene-diamine and atropine she slowly improved, but two days later she aborted. Following abortion her general condition improved rapidly, but she still had extensive œdema and the liver border was two inches below the umbilicus. A few days later the œedema and venous congestion had considerably lessened but her cough had increased and moist sounds were heard in the chest. At the same time she began to have attacks of paroxysmal dyspnœa lasting several hours. On October 20 at 6 a.m. she suddenly became intensely dyspnœic, moist sounds were audible over the whole chest, and she coughed up considerable amounts of frothy sputum. She was pulseless and very cyanosed. With oxygen, atropine, and intramuscular theophylline-ethylene-diamine she improved temporarily but then relapsed and died at $10.40 \mathrm{a} . \mathrm{m}$.

Autopsy was performed by Dr. W. Susman, 24 hours after death. The lungs were œdematous and the right pleura contained about a litre of clear fluid. There was passive congestion of all organs. The heart weighed $260 \mathrm{~g}$.; the right ventricle was considerably hypertrophied, and the left auricle was dilated and greatly hypertrophied. The mitral valve exhibited a severe degree of stenosis, the orifice measuring $5 \mathrm{~mm}$. $\times 10 \mathrm{~mm}$.; there were small recent rheumatic vegetations on the valve. The aortic valve was healthy but the thoracic aorta showed two patches about $2 \mathrm{~cm}$. in diameter of a pearly grey colour with numerous longitudinal puckerings-appearances suggestive of a rheumatic aortitis. The pulmonary arteries exhibited considerable atheroma. Apart from slight scarring of the capsular surfaces and severe passive congestion the kidneys appeared healthy. The uterus was enlarged $(8 \times 10 \times 3.5 \mathrm{~cm}$. $)$ and the cavity was filled with adherent thrombus.

Histological examination showed diffuse fibrosis of the auricular muscle, and a patchy, mainly perivascular, fibrosis of both ventricles, more severe on the left. The appearances of the aortic lesions were typical of rheumatic aortitis.

\section{Discussion}

In 1872 Peter described a typical severe attack of pulmonary œdema occurring during the fifth month of pregnancy from which recovery occurred following venesection and emetics, but which recurred at the same stage of a subsequent pregnancy when he was able to detect characteristic signs of mitral stenosis with a presystolic murmur. His description makes it clear that normal rhythm was present, and in a detailed account of the auscultatory findings he makes no mention of any other diastolic murmur. Thus, in the stage of pregnancy, the presence of normal rhythm, and of a murmur confined to auricular systole, Peter's case resembles those we have described. Subsequently cases were described by several workers, mostly in France and in America (Jensen, 1938).

Two main hypotheses have been put forward to account for the development of acute pulmonary œdema in pregnancy-the "toxic" and the "mechanical." Vinay (1896) described pulmonary œdema in a pregnant woman with chronic nephritis but no heart disease, and a second case, fatal in the fifth month of pregnancy, in a woman with heart disease and albuminuria, which he attributed to renal damage. Pouliot (1904) collected reported cases of pulmonary œdema and found that renal damage was present in many of them. The view generally accepted seems to have been that of Schellong (quoted by Laennec, 1930) that as pulmonary œdema could not be mechanical it must be "toxic." There now appears to be little satisfactory evidence to support the toxic hypothesis, and even in cases of renal disease with hypertension, pulmonary œdema is usually ascribed to left ventricular failure. In our cases, however, there was no hypertension during life and no evidence of renal disease at autopsy. 
In left ventricular failure there is no clear dividing line between pulmonary congestion and acute pulmonary œdema; similarly, in mitral stenosis pulmonary congestion and its rarer sequel, acute pulmonary œdema, differ only in degree and are produced by the same mechanism. That mechanism may now be considered.

From his experimental observations on the dynamics of the circulation Wiggers (1923) showed that, under normal conditions, ventricular diastole may be divided into three phases (Fig. 1, A):

(a) In early diastole, when the mitral valve first opens, the blood flows rapidly from the auricle into the empty ventricle.

\section{AURICULAR PRESSURE AND VENTRICULAR FILLING IN MITRAL STENOSIS}

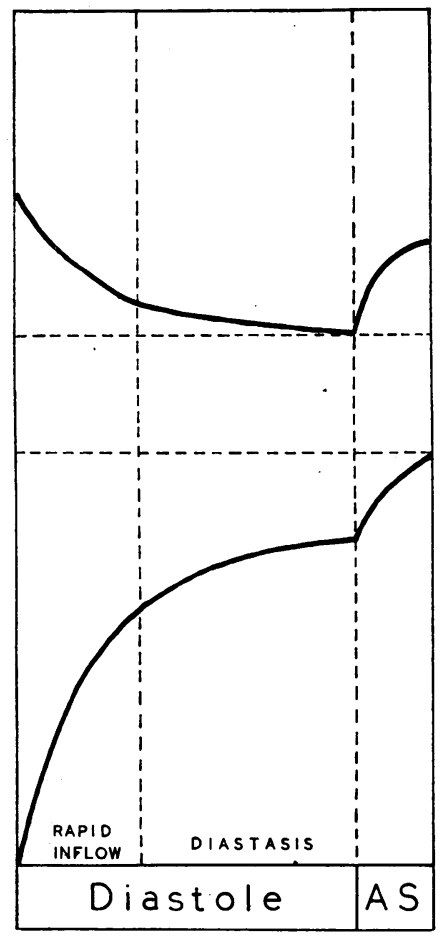

(A) NORMAL

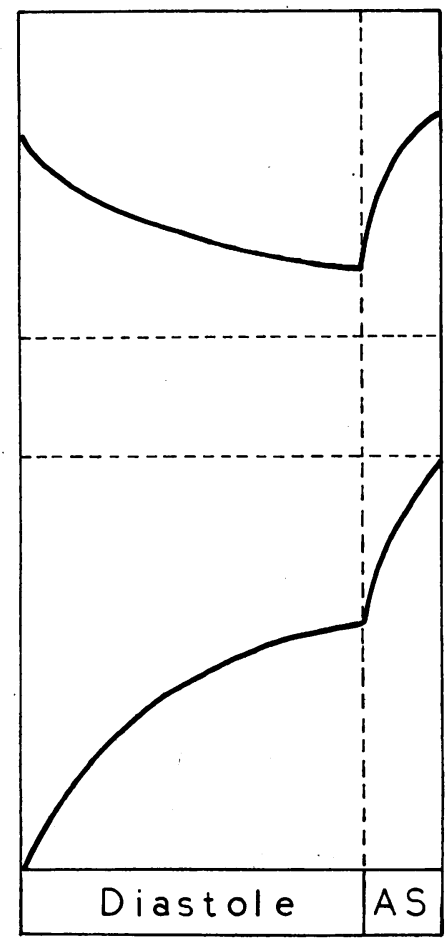

(B)MITRAL STENOSIS WITH

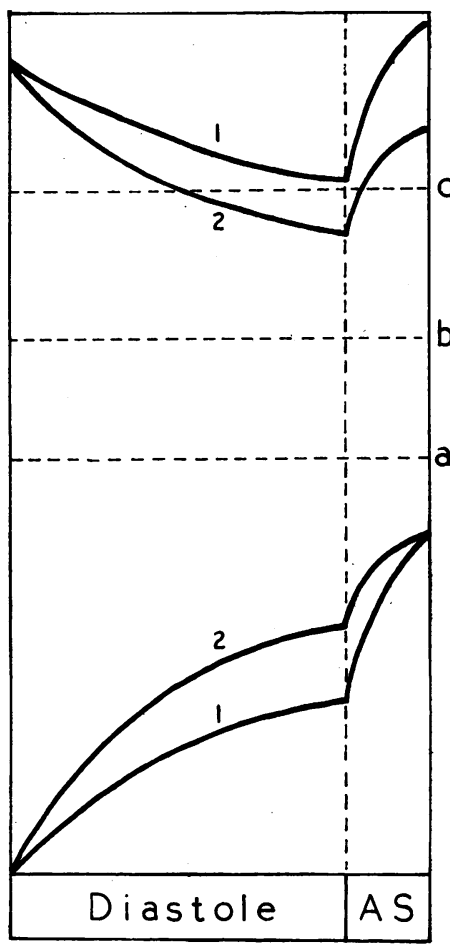

(C)MITRAL STENOSIS WITH

FIG. 1.-The upper curves represent diagrammatically the auricular pressure and the lower curves the ventricular volume during diastole and auricular systole (AS).

$a$ is the volume of the ventricle when filling is complete;

$b$ is the normal auricular diastolic pressure at the onset of auricular systole :

$c$ is the level of auricular diastolic pressure (and of pulmonary venous pressure) which would lead to a rise of pulmonary arterial blood pressure.

$(A)$ represents the normal course of events during diastole when the heart rate is slow. During the period of rapid inflow the ventricular volume rapidly increases and the auricular pressure falls correspondingly. During diastasis there is comparatively little ventricular filling. At the onset of auricular systole the ventricle is already almost full, so that the auricle plays only a small part in ventricular filling.

$(B)$ represents the events during diastole when faultlessly compensated mitral stenosis is present. Owing to the obstruction to ventricular filling the ventricular volume rises more slowly and the auricular pressure falls correspondingly slowly. At the onset of auricular systole the ventricle is far from full and the auricular diastolic pressure higher than normal. For both these reasons auricular systole makes an abnormally large contribution to ventricular filling.

$(C)$ represents the events when left ventricular filling is no longer maintained ("left-sided failure ").

1 shows how an increased obstruction at the mitral valve causes slower ventricular filling, and an auricular contribution equal to that in $(B)$ fails to bring ventricular filling to normal ;

2 shows how the same result occurs when the auricle fails to supply its quota, the mitral stenosis remaining unchanged.

In these circumstances the elevation of the auricular diastolic pressure (and pulmonary venous pressure) above $c$ would lead to pulmonary arterial hypertension and right ventricular hypertrophy. 
(b) In mid-diastole, when the initial difference in pressure between auricle and ventricle has been relieved, the blood current is much more sluggish. To this phase he gave the name " diastasis."

(c) In presystole, when the auricle contracts, the rate of blood flow is again increased.

When the mitral orifice is stenosed, it takes longer to equalize the pressures in auricle and ventricle; consequently the rate of ventricular filling during early and mid-diastole becomes more uniform.

When stenosis is severe the pressure in the auricle remains considerably higher than that in the ventricle throughout early and mid-diastole, and when auricular systole supervenes the auricular wall is still under considerable tension. This, in accordance with Starling's (1918) law, evokes a more powerful auricular contraction, and the dilated auricle develops a compensatory hypertrophy.

As the auricular diastolic pressure rises the pulmonary pressure rises with it, first on the venous side, leading to congestion in the lungs, and later on the arterial side, so that the burden is thrown back upon the right ventricle.

Fishberg (1940) has accordingly described the evolution of mitral stenosis in three stages (Fig. 1, B and C):

(1) A stage of faultless compensation dependent on prolongation of the phase of " rapid inflow " at the expense of "diastasis," and auricular hypertrophy.

(2) A stage of failure of the left side * of the heart with pulmonary engorgement, a rise of pulmonary arterial pressure, and hypertrophy of the right ventricle.

(3) A stage of failure of the right side of the heart with systemic venous engorgement.

A case will pass from the first to the second stage if the valvular stenosis increases, or if the compensatory mechanisms break down owing to a weakening of auricular systole or to the onset of auricular fibrillation (Fig. 1, C (1 and 2)). In either event, ventricular filling can only be maintained by an increase of the auricular diastolic pressure. This increase in pressure is transmitted to the pulmonary veins, producing chronic pulmonary congestion and perhaps hæmoptysis. It is usual for the signs of pulmonary congestion to develop gradually, as the slowly increasing stenosis leads to gradual left auricular failure.

In both our cases, however, pulmonary congestion developed suddenly and led to acute pulmonary œdema. A sudden increase of pulmonary venous pressure may be due either to a sudden increase in mitral obstruction or to acute left auricular failure. The former might occur if the mitral valve were suddenly occluded by a ball thrombus, but in our cases no auricular thrombus was present at autopsy.

The possibility of sudden left auricular failure being responsible for the development of acute pulmonary œdema in cases of mitral stenosis depends on the extent to which auricular systole contributes to ventricular filling. Kerkhof's (1936) observations on the cardiac output in mitral stenosis with auricular fibrillation, before and after the restoration of sinus rhythm with quinidine, led him to conclude that auricular contraction was responsible for about 25 per cent of ventricular filling, but in these experiments he made no allowance for the rise in the auricular diastolic pressure associated with fibrillation, $\uparrow$ which is an important factor in maintaining ventricular filling. Further, fibrillation is more likely to occur in auricles that have been severely damaged by the original rheumatic infection, and his experiment, therefore, fails to give a true measure of the effect of systole in the more healthy auricle that has never fibrillated. For these two reasons it seems probable that Kerkhof's estimate of the part played by auricular systole is unduly conservative.

This is confirmed by Wiggers and Katz' (1922) observations on the varying contribution of the auricle to ventricular filling at different heart rates. When diastole is prolonged the ventricle is already almost full when the auricle contracts; in these circumstances, auricular

* Presumably Fishberg referred to failure of the left auricle since, in mitral stenosis, failure of the left side of the heart could not be due to ventricular failure.

$\dagger$ Unpublished personal observations in experimental fibrillation. 
systole accounts for only 10 per cent of ventricular filling. When, however, the heart is beating rapidly, and diastole is short, the auricle contracts when the ventricle is only partially filled; in these circumstances 50-60 per cent of ventricular filling may be due to auricular systole. The effect of mitral stenosis is comparable to that of tachycardia; owing to the reduced rate of blood flow through the mitral valve, ventricular filling is far from complete at the onset $o$ auricular systole, so that auricular contraction becomes correspondingly more important in maintaining ventricular filling.

In our two cases the severe degree of stenosis found at autopsy, coupled with the fact that during life the murmur was confined to pre-systole, suggests that the amount of blood passing through the mitral orifice during early diastole was insufficient to produce a murmur. If this be true, ventricular filling in such cases would be largely dependent on auricular systole. In order to maintain ventricular filling under these circumstances auricular systole must be powerful, and in both our cases the wall of the left auricle was greatly hypertrophied.

In severe mitral stenosis, when ventricular filling is largely dependent on auricular systole, if sudden failure of the auricle occurs, ventricular filling will then depend solely upon an auricular diastolic pressure previously inadequate to effect any substantial filling. Adequate filling can only be re-established if the auricular diastolic pressure rises rapidly. If this occurs, it will lead to a corresponding rise of pulmonary venous pressure, with sudden pulmonary congestion and ultimately acute pulmonary œdema (Case 1).

Gerhardt (quoted by Fishberg, 1940) showed in animal experiments that if the pulmonary venous pressure rose above $7 \mathrm{~cm}$. of water the pulmonary arterial pressure began to rise. Thus if the sudden rise of pulmonary venous pressure reaches a sufficiently high level, a sudden rise of pulmonary arterial pressure will follow, and this may lead to acute right ventricular failure (Case 2).

The combination of severe mitral stenosis with an efficient auricle is only likely to occur if the original rheumatic infection is associated with severe mitral endocarditis but comparatively little auricular myocarditis, and the infrequency of this combination may account for the comparative rarity of the syndrome. In the majority of cases, acute rheumatic carditis leads to a moderate degree of mitral stenosis coupled with a correspondingly severe lesion of the auricular myocardium, which predisposes to auricular fibrillation. In that case a moderately raised auricular pressure may be sufficient to maintain ventricular filling but if ventricular filling is to be maintained as the stenosis increases, the auricular pressure must continue to rise, so leading to gradually increasing pulmonary congestion. In Table I we have endeavoured to compare the sequence of events in chronic and acute left auricular failure.

TABLE I

Left Auricular Failure

\begin{tabular}{|c|c|c|c|c|c|c|}
\hline & & & & & Chronic & Acute \\
\hline $\begin{array}{l}\text { Mitral endocarditis } \\
\text { Left auricular myocarditis }\end{array}$ & $\cdot$ & $\cdots$ & $\cdots$ & . & $\begin{array}{l}+\quad+ \\
+\quad+\end{array}$ & $+\underset{+}{+}+$ \\
\hline $\begin{array}{l}\text { Mitral stenosis } \\
\text { Left auricular hypertrophy }\end{array}$ & $\begin{array}{l}\cdots \\
\cdots\end{array}$ & $\begin{array}{l}\cdots \\
\cdots\end{array}$ & $\begin{array}{l}\cdots \\
\cdots\end{array}$ & $\cdots$ & $+t$ & $\begin{array}{l}+++ \\
+++\end{array}$ \\
\hline 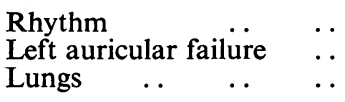 & $\begin{array}{l}\cdots \\
\cdots \\
\cdots\end{array}$ & $\begin{array}{l}\cdots \\
\cdots \\
\cdots\end{array}$ & $\begin{array}{l}\cdots \\
\cdots \\
\cdots\end{array}$ & $\begin{array}{l}\cdots \\
\cdots \\
\cdots\end{array}$ & $\begin{array}{l}\text { Auricular fibrillation } \\
\text { Chronic } \\
\text { Chronic congestion }\end{array}$ & $\begin{array}{l}\text { Normal } \\
\text { Acute } \\
\text { Acute œdema }\end{array}$ \\
\hline
\end{tabular}

Both our patients died in mid-pregnancy and it seems probable that the increasing blood volume and rising heart output at this stage of pregnancy were factors in precipitating heart failure. 


\section{SUMMARY}

Two cases of mitral stenosis with acute pulmonary œdema leading to death about the middle stage of pregnancy are described.

The mechanism of production of this complication is discussed and it is attributed to acute left auricular failure.

We are indebted to Professor S. L. Baker for the pathological work, which was carried out in his Department.

\section{REFERENCES}

Fishberg, A. M. (1940) Heart Failure, London, p. 502.

Jensen, J. (1938). The Heart in Pregnancy, St. Louis, p. 226.

Kerkhof, A. C. (1936). Amer. Heart J., 11, 206.

Laennec, Th. (1930). Cardiopathies mitrales et gestation, These, Paris.

Peter, M. (1872). L'Union Medicale, 13, 278.

Pouliot, L. (1904). Quoted by Jensen (1938).

Starling, E. H. (1918). The Law of the Heart, Linacre Lecture, London.

Vinay, C. (1896). Lyon. Med., 83, 289.

Wiggers, C. J. (1923). Circulation in Health and Disease, Philadelphia, p. 99.

Wiggers, C. J., and Katz, L. N. (1922). Amer. J. Physiol., 58, 439. 